\title{
Education
}

\section{Complementary and Alternative Medicine Familiarization: What's happening in Medical Schools in Wales?}

\author{
Natalie Taylor ${ }^{1}$ and Anona Blackwell ${ }^{2}$ \\ ${ }^{1}$ Department of General Surgery and ${ }^{2}$ Department of Genito-Urinary and HIV Medicine, Singleton Hospital, \\ Sketty Lane, Swansea, SA2 8QA, Wales, UK
}

\begin{abstract}
Despite recommendations that complementary and alternative medicine (CAM) familiarization should be offered to UK medical students, in Wales little such teaching was offered. We decided to assess medical students' knowledge of CAMs, perceived training needs in CAMs, their view of its role in the National Health Service (NHS) and current teaching given. Analysis of data from a questionnaire given to medical students and direct questioning of senior academic medical school staff in Cardiff and Swansea Medical Schools was carried out. The participants comprised 78 first year medical students in the undergraduate entry program in Cardiff and 58 first year medical students from the graduate entry program in Swansea. Senior academic medical school staff at Cardiff and Swansea Medical Schools were asked about current CAM teaching. Results revealed that $32 \%$ of undergraduate entry students (UGES) had previous knowledge of CAMs compared with $51 \%$ of graduate entry students (GES). Of the UGES, $62 \%$ believed they should be taught about CAM's compared with $94 \%$ of GES. Of UGES $31 \%$ felt that CAMs have a role in the NHS compared with $50 \%$ of GES. None of the students had received teaching about CAMs and little formal CAM teaching is currently included in the curricula at each site. The majority of medical students in Wales would like to receive CAM teaching and significant numbers support a role for CAMs in the NHS. Little formal teaching is currently provided.
\end{abstract}

Keywords: CAM teaching-medical students-integrated healthcare

\section{Introduction}

In 'Tomorrows Doctors' published in 2003, the General Medical Council (GMC) stated that students must be aware that many patients are interested in and choose to use a range of alternative and complementary therapies. Graduates must be aware of the existence and range of such therapies, why some patients use them, and how these might affect other types of treatment that patients are receiving (1). The British Medical Association (BMA)

For reprints and all correspondence: A. Blackwell, Consultant in Genito-Urinary Medicine, Department of Genito-Urinary and HIV Medicine, Singleton Hospital, Sketty Lane, Swansea, SA2 8QA, Wales, UK. Tel: 01792-205666 ext 5083; Fax: 01792-285093;

E-mail: anona.blackwell@swansea-tr.wales.nhs.uk also recognized the need for teaching of complementary and alternative medicines (CAMs) in medical schools (2) and government concern about the increased use and relative lack of regulation of CAMs led to an investigation of CAMs by the House of Lords Select Committee (3). The Select Committee report, which was published in 2000, made recommendations concerning the teaching of CAMs to healthcare staff including medical students and doctors. These recommendations included:

- 'Familiarisation (with $C A M s$ ) should prepare medical students for dealing with patients who are either accessing CAMs or have an interest in doing so. This familiarisation should cover the potential uses of CAMs, the procedures involved, their potential benefits and their main weaknesses'. 
- 'That every medical school ensures that all their medical undergraduates are exposed to a level of CAM familiarisation that makes them aware of the choices their patients make'.

- 'Royal Colleges and other training authorities in the healthcare field should address the issue of familiarisation with CAM therapies among doctors, dentists and veterinary surgeons by supporting appropriate Continuing Professional Development opportunities'.

The House of Lords Select Committee commented on CAM teaching at a number of UK Medical Schools including University of Wales College of Medicine UWCM, now Cardiff University Medical School. At Cardiff it was noted, 'that little or no teaching is devoted to complementary medicine, though a Special Study Module in this subject is offered' (3).

The recommendations made by this committee were fully endorsed by the government in its response in March 2001 (4) and the Royal College of Physicians set up a Complementary and Alternative Medicine Committee, which held its first meeting in London in October 2001.

In May 2006 a letter was sent by a group of doctors headed by Michael Baum, Emeritus Professor of Surgery at University College of London, to the chief executives of UK National Health Service (NHS) Trusts. The group suggested that NHS trusts should not pay for CAMs and subsequent public debate included support for CAMs by the Prince of Wales (5).

The above led us to seek the views of first year medical students attending medical schools in Wales. Our aim was to seek their current knowledge on CAMs, perceived teaching needs, what role they felt CAMs may have in the NHS and what CAM teaching was currently provided.

\section{Design and Participants}

A voluntary questionnaire (Fig. 1) concerning various aspects of CAMs was distributed to 80 of 300 first year undergraduate entry students (UGES) who were attending a compulsory dissection class in October 2006 at Cardiff University Medical School. Students were selected because they were assigned to library tasks rather than actual dissection, making completion of the questionnaires easier. Similarly, questionnaires were also handed out to all 65 of 71 first year graduate entry medical students (GES) who attended a compulsory clinical conference at Swansea Medical School in November 2006. In order to compare like with like, Cardiff students in the undergraduate intake who had previous degrees were added to their peer group in the Swansea graduate entry intake. The data was then collated to see if there were differences between the UGES and GES groups and if there were any gender related differences between the men and women in the combined groups.

Seventy-eight of 80 questionnaires given to the Cardiff undergraduate entry medical students were returned; four students had previous degrees and were added to the Swansea graduate entry medical student group. Fiftyeight of 65 questionnaires were returned by the GES group. After reallocating the four Cardiff graduate students there were 74 in the UGES group and 62 in the GES group. Twenty-two students in the UGES group and 17 in the GES did not state their age. The mean age of 52 of 74 students in the UGES group was 18.5 years [range (18-23 years)]. Similarly, the mean age of 45 of 62 students in the GES group was 24.6 years [range (21-37 years)]. There were $51(69 \%)$ women in the UGES group compared with $26(42 \%)$ women in the GES group.

To assess current teaching provisions for CAMs, we approached senior academic medical school staff at each site.

\section{Results}

\section{Knowledge and Personal Experience of CAMs}

Of the 74 UGES, twenty-four students (32\%) comprising nine men and 15 women said they had knowledge on CAMs but only 7, (9.4\%), one man and six women had personally experienced CAMs. Similarly, of the 62 GES, $32(51 \%), 17$ men and 15 women had knowledge on CAMs and 18(29\%), five men and 13 women, had personally experienced CAMs. This difference is statistically significant $(P<0.001)$.

\section{Should Medical Students Have a Basic Knowledge of CAMs?}

Of the UGES, 62\% (15 men and 31 women) believed that medical students should have a basic knowledge of CAMs. Of the GES group 94\% (33 men and 25 women) felt that teaching medical students CAMs was necessary. The difference between the groups is statistically significant, $P<0.001$.

\section{If Yes, which CAM(s) Do You Consider Important?}

Of 136 students only 42 responded so the results were collated for the combined group. CAMs that were considered important were acupuncture 27/42(64\%), herbal medicine $16 / 42(38 \%)$, chiropractic $13 / 42(31 \%)$, osteopathy $11 / 42(26 \%)$, homeopathy $5 / 42(12 \%)$ and reflexology and Tai Chi 3/42(7\%) each. Aromatherapy was not mentioned. 
CAM Questionnaire

About yourself:

Age

Gender Male $\square \quad$ Female

Previous further education (BSc etc) No $\square \quad$ Yes $\square$

What year are you?

Complementary therapies

1) Do you have any previous knowledge of CAMs?

No $\square \quad$ Yes $\square \quad$ If Yes, which ones?

2) Have you ever personally experienced any CAMs service?

No $\square \quad$ Yes $\square \quad$ If Yes, which ones?

3) Do you believe medical students should have a basic knowledge of CAMs?

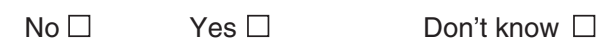

If Yes, which ones do you think are important?

4) Do you feel CAMs have a role in the NHS?

No $\square \quad$ Yes $\square \quad$ Don't know $\square$

5) Have you received or been offered any CAM training whilst at Medical School

No $\square \quad$ Yes $\square \quad$ If Yes please say what

6) If Yes to $Q 5)$, do you feel the training was adequate?

No $\square \quad$ Yes $\square$

Any other comments:

Thank you for your time.

Figure 1. Medical students understanding/perceived training needs in CAMs ${ }^{\mathrm{a}}$.

Do You Feel CAMs Have a Role in the NHS?

Of UGES, $23 / 74(31 \%)$ felt that CAMs had a role in the NHS, $30(41 \%)$ did not know and $21(28 \%)$ said no. This compared with $31(50 \%)$ of GES who believed CAMs had a role, $21(34 \%)$ who did not know and $10(16 \%)$ said no. The difference between the two groups is statistically significant $(P$-value $<0.005)$.

Have You Been Offered or Received any Training about CAMs?

No student from either the UGES or GES groups had received or been offered any CAMs training.

\section{Gender Differences in the Combined Groups?}

Within the combined GES and UGES there were no statistically significant gender differences for perceived knowledge of CAMs, the role of CAMs in the NHS and need for teaching on the subject. However, there was a difference between males and females personal use of CAMs. Of the women, $31 \%$ had used CAMS compared with $9 \%$ of men.

\section{Current CAM familiarization provided within the curriculum.}

In both Cardiff and Swansea, senior academic staff noted that little formal CAM familiarization was provided within the core curriculum.

\section{Discussion}

\section{Knowledge and Personal Experience of CAMs}

In our study, the GES had more personal experience and knowledge on CAMs than the younger UGES group. There was a gender difference in personal CAM use 
overall with female students more likely to have personally experienced CAMs. In a similar study to ours in 1999, first year medical students in the UK were asked to rate CAM therapies following a core teaching session. In agreement with our findings, it was found that female students had used CAMs more than their male colleagues. However, there was no significant gender difference regarding their rating of the therapies after a core teaching session (6). Our results largely agree with this and we believe that the differences seen in our UGES and GES are almost certainly due to age differences and related life experience. The differences may also be related to the subjects of GES first degrees but this data was not collected.

\section{Should Medical Students Have a Basic Knowledge of CAMs?}

Most of our students said they should have a basic knowledge on CAMs with an impressive $94 \%$ of the GES group wanting CAM familiarization. Fewer of the UGES $(62 \%)$ felt they needed CAM education but this could be because the UGES had less personal experience in the area. In agreement with our results several studies have shown that medical students are interested in learning about CAMs $(2,7-14)$ and one study showed that $69 \%$ of students believe that alternative practitioners can provide effective treatment (7). Such familiarization is important because CAMs are widely available in UK hospitals (15) and many patients use CAMs. A study, which investigated the use of CAMs in dermatology patients revealed that half of over 400 patients attending the dermatology departments in Cardiff and Swansea were using CAMs to treat their skin problems. The most popular therapies were homeopathy and herbal medicine (16). It is likely that patients attending other specialist clinics may also be using CAMs, some of which could have adverse effects such as drug interactions with St Johns Wort, allergic reactions with tea tree oil and rarities such as prepubertal gynecomastia linked with essential oils (16-19). This is supported by a study from North East Scotland concerning CAM use by local residents, which revealed increased usage of aromatherapy, acupuncture and reflexology over the study period of 1993-1999 (20). Furthermore, serious medical conditions may be alleviated by CAMs and a recent review of cardiovascular disease in The Lancet discussed the role of stress in its etiology (21). Many CAMs have been shown to be effective in stress reduction (22) so, we feel it is important that healthcare workers have a knowledge on both allopathic and CAM approaches to stress management. Therefore, we endorse the view that medical students, doctors and other healthcare workers should have a working knowledge on CAMs and of their possible benefits and side effects.

\section{What CAMs are Important?}

Our results showed that our students were interested in learning about acupuncture, herbal medicine, chiropractic, osteopathy and homeopathy but curiously, not aromatherapy, which was popular with other students and patients $(6,16)$. Greenfield et al. (6) asked first year medical students, which CAM therapies they wished to study. The most popular treatments were chiropractic, hypnotherapy, aromatherapy and acupuncture. Clearly all these CAMs should be included in any proposed famliarization course but of greater importance is familiarization with CAMs most commonly actually used by patients.

\section{Should CAMs Have a Role in the NHS?}

A significant proportion of our students felt that CAMs should have a role in the NHS and though many were undecided, relatively few felt that CAMs should be excluded. We feel that patient demand may eventually lead to increased use of CAMs within the NHS. In a combined study of over 700 patients attending dermatology outpatients in Leeds, Swansea and Cardiff, 75\% felt that CAMs should be available within the NHS and $88 \%$ felt they should be considered alongside conventional medicine (16). Unfortunately, the NHS does not have infinite resources, so cost is a major consideration when new services are proposed. Britons currently spend $£ 130$ million a year on complementary treatments (23) and it is unlikely that the NHS could support all CAMs but perhaps some may be integrated. Already CAMs, including reflexology, aromatherapy and reiki are widely used in palliative care and oncology services and in some trusts acupuncture is used for pain relief $(15,24)$. One study showed an increase in pain free days in patients who underwent acupuncture for pain related to osteoarthritis of the knees and reported a reduction in the number of days' pain medication was required (25). Therefore, it may be that the introduction of some CAMs, such as acupuncture would lead to lower drug bills thus making the treatment more financially appealing.

\section{Have You Received any Training in CAMs? And if so was it Adequate?}

None of our students had received any CAM familiarization, though they were only in their first year of training. However, from the responses from academic staff at each site little formal CAM teaching is currently provided on either course. This is at odds with the recommendations for undergraduate training given by the GMC in Tomorrow's Doctors (1). The BMA also recommends that medical students should be provided with awareness education about CAMs during their 
undergraduate studies (26) and a survey by Morgan et al. (10) 1998, indicated that an increase in CAM information provided to undergraduate doctors is needed if they are to meet the increasing requests by patients for guidance on CAMs. Medical schools in Wales do not yet appear to have addressed this issue and we agree with Rampes et al. (9) who, finding that medical students would like more education on complementary medicine, suggested that 'a national core syllabus on complementary medicine be devised in consultation with organizations that teach complementary medicine to registered health professionals'. We agree with this suggestion, which would ensure that appropriate CAM teaching was available throughout the UK.

\section{Conclusions}

Arguments for and against the provision of CAMs within the NHS remain a political and medical issue and the suggestion that the National Institute for Health and Clinical Excellence should evaluate CAMs has been recently debated $(27,28)$. Some familiarization with CAMs for medical students and doctors is less controversial and was the view stated in the House of Lords Select Committee's Report on CAMs in 2000. However in Wales, 6 years after this report, and despite endorsement from the GMC and BMA, the medical student curricula are still not offering such familiarization. Our survey conclusively shows that our medical students wish to learn about CAMs and, in particular, postgraduate entry students recognize the need for such education. We feel that little progress will be made unless a national core syllabus on CAMs is developed and appropriate legislation introduced.

\section{Acknowledgements}

We thank Dr George Lewith, Reader in Complementary Medicine, University of Southampton for his help in the questionnaire design and editorial comments and Jonathan Barlow BSc, Cardiff University Medical School for help with statistical analysis of the data.

\section{References}

1. General Medical Council. Tomorrow's doctors: Recommendations on undergraduate medical education. London: GMC, 2003.

2. British Medical Association. Complementary Medicine: New Approaches to Good Practice. Oxford: OUP, 1993.

3. House of Lords Science and Technology- Sixth Report. Complementary and alternative medicine. London: House of Lords, HMSO, 2000.

4. Government Response to the House of Lords Select Committee on Science and Technology's Report on Complementary and Alternative Medicine. HMSO, 2001.

5. A speech by HRH The Prince of Wales for the first conference of The Prince of Wales's Foundation for Integrated Health
G.P. Associates, London. 11th October 2005. Available at: http:// news.bbc.co.uk/1/hi/wales/3738612.stm

6. Greenfield SM, Innes MA, Allan TF, Wearn AM. First year medical students' perceptions and use of complementary and alternative medicine. Complement Ther Med 2002;10:27-32.

7. Furnham A, Hanna A, Vincent CA. Medical students' attitudes to complementary medical therapies. Complement Ther Med 1995;3:212-9.

8. Lewith G, Breen A, Filshie J, Fisher P, McIntyre M, Mathie R, et al. Complementary medicine: evidence base, competence to practice and regulation. Clin Med 2003;3:235-40.

9. Rampes H, Sharples F, Maragh S, Fisher P. Introducing complementary medicine into the medical curriculum. $J R$ Soc Med 1997;90:19-22.

10. Morgan DR, Glanville H, Mars S, Vera V. Education and training in complementary and alternative medicine: a postal survey of UK universities, medical schools and faculties of nurse education. Compliment Ther Med 1998;6:64-70.

11. Furnham A. Attitudes to alternative medicine: a study of the perceptions of those studying orthodox medicine. Complement Ther Med 1993;1:120-6.

12. Reilly D, Taylor M. Developing integrated medicine. Report of the RCCM Resource Fellowship in complementary medicine, the University of Glasgow 1987-1990.

13. Haramati A, Lumpkin MD. Integrating complementary and alternative medicine in to conventional medical education: role of basic science. Arch Intern Med 2001;161:1679.

14. Chaterji R, Tractenberg RE, Amir H, Lumpkin M, Amorosi SBW, Haramati A. A large-sample survey of first-and second-year medical students attitudes towards complementary and alternative medicine in the curriculum and in practice. Alt Ther 2007;13:30-5.

15. Kohn M. Directory of Complementary Therapy Services in UK Cancer Care. Public and Voluntary Sectors. London: Macmillan Cancer Relief/Cambridge Publishers, 2002.

16. Baron S, Goodwin R, Nicolau N, Blackford S, Goulden V. Use of complementary medicine among outpatients with dermatological conditions within Yorkshire and South Wales, United Kingdom. J Am Acad Dermatol 2005;52:589-94.

17. Marcus M. Drug interactions with St John's Wort. Mechanisms and clinical implications. Drug Saf 2004;27:773-97.

18. Varma S, Blackford S, Statham BN, Blackwell A. Combined contact allergy to tea tree oil and lavender oil complicating chronic vulvovaginitis. Contact Dermat 2000;42:309.

19. Henley D, Lipson N, Korash K, Bloch C. Prepubertal gynaecomastia linked to lavender and tea tree oils. $N$ Engl J Med 2007;356:479-85.

20. Emslie MJ, Campbell MK, Walker KA. Changes in public awarness of, attitudes to, and use of complementary therapy in North East Scotland: surveys in 1993 and 1999. Complement Ther Med 2002;10:148-53.

21. Brotman DJ, Golden SH, Wittstein IS. The cardiovascular toll of stress. The Lancet 2007;370:1089-100.

22. Balinski AA. Use of Western Australian flower essences in the management of pain and stress in thehospital setting. Complement Ther Nurs Midwifery 1998;4:111-7.

23. Fleming N. NHS complementary therapy 'could save billions'. The Daily Telegraph July 10, 2003.

24. Burden B, Herron-Marx S, Clifford C. The increased use of Reiki as a complementary therapy in specialist palliative care. Int $J$ Palliat Nurs 2005;11:5.

25. Witt C, Brinkhaus B, Jena S, Linde K, Streng A, Wagenpfeil S, et al. Acupuncture in patients with osteoarthritis of the knee: a randomised trial. The Lancet 2005; V366.

26. Bermen B, Singh BK, Lao L, Singh BB, Ferenz KS, Hartnoll SM, et al. Complementary medicine and medical education; teaching complementary medicine offers a way of making teaching more holistic. BMJ 2001;322:121-2.

27. Franck L, Chantler C, Dixon M. Should NICE evaluate complementary and alternative medicine? YES. BMJ 2007;334:506.

28. Colquhoun D. Should NICE evaluate complementary and alternative medicine?: NO. BMJ 2007;334:507.

Received December 5, 2007; accepted December 18, 2007 


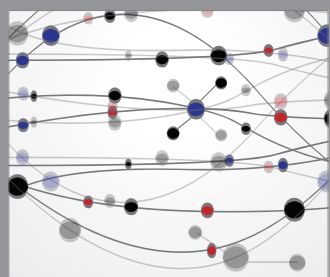

The Scientific World Journal
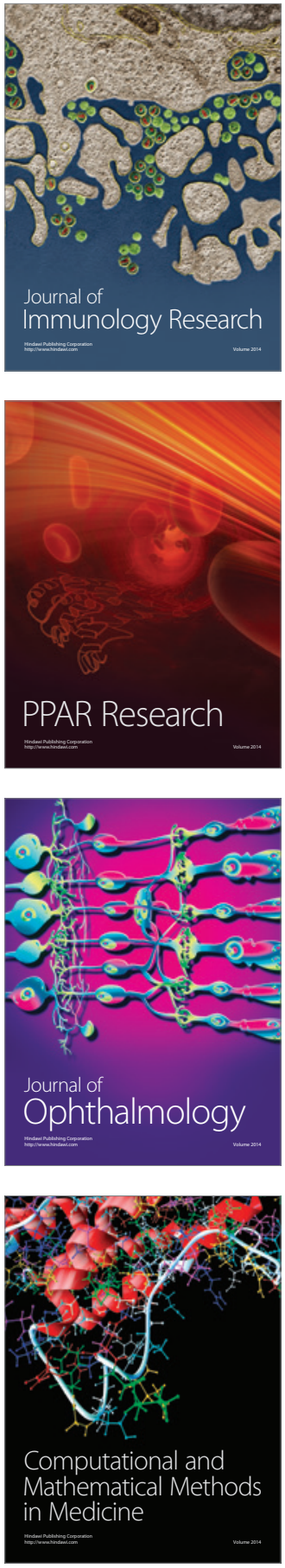

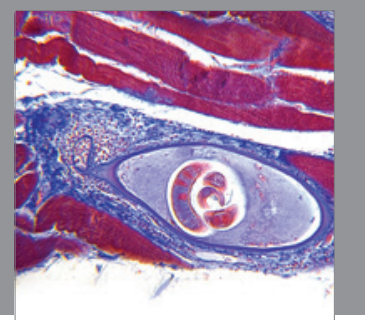

Gastroenterology

Research and Practice
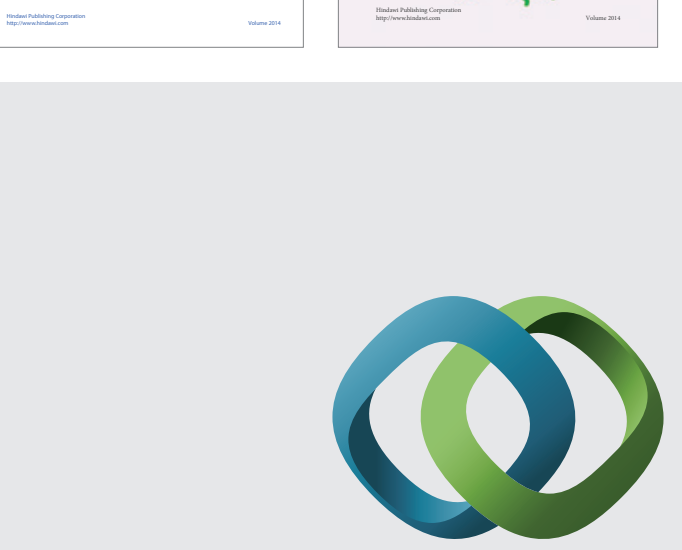

\section{Hindawi}

Submit your manuscripts at

http://www.hindawi.com
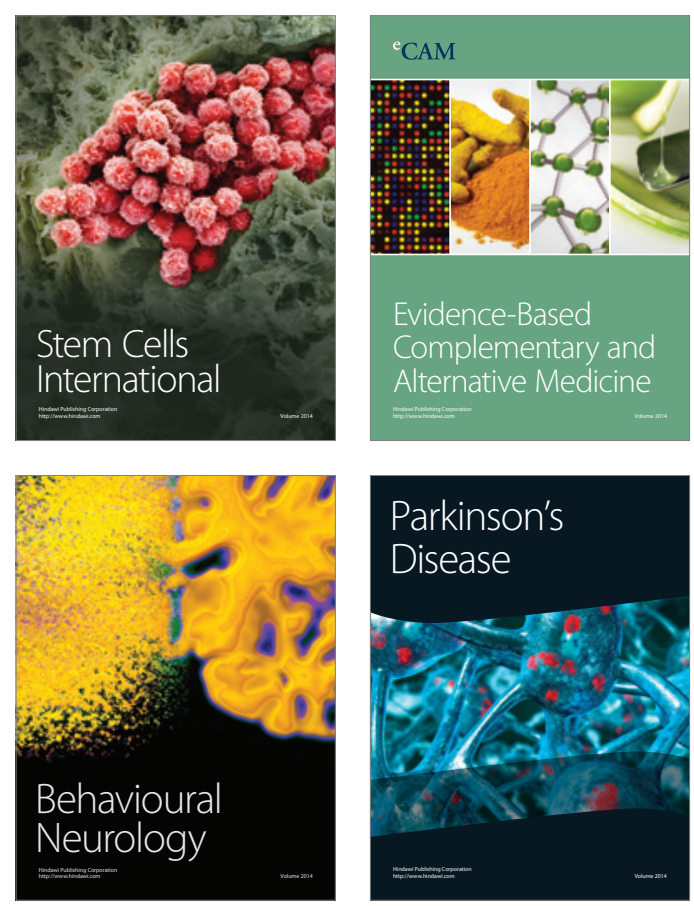

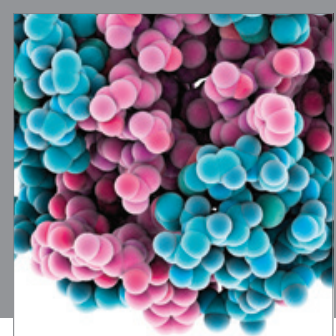

Journal of
Diabetes Research

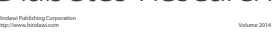

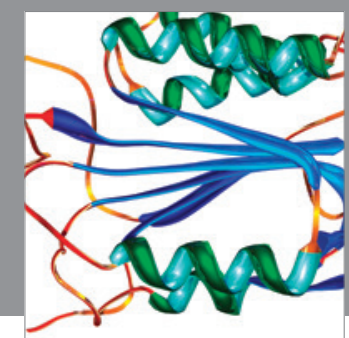

Disease Markers
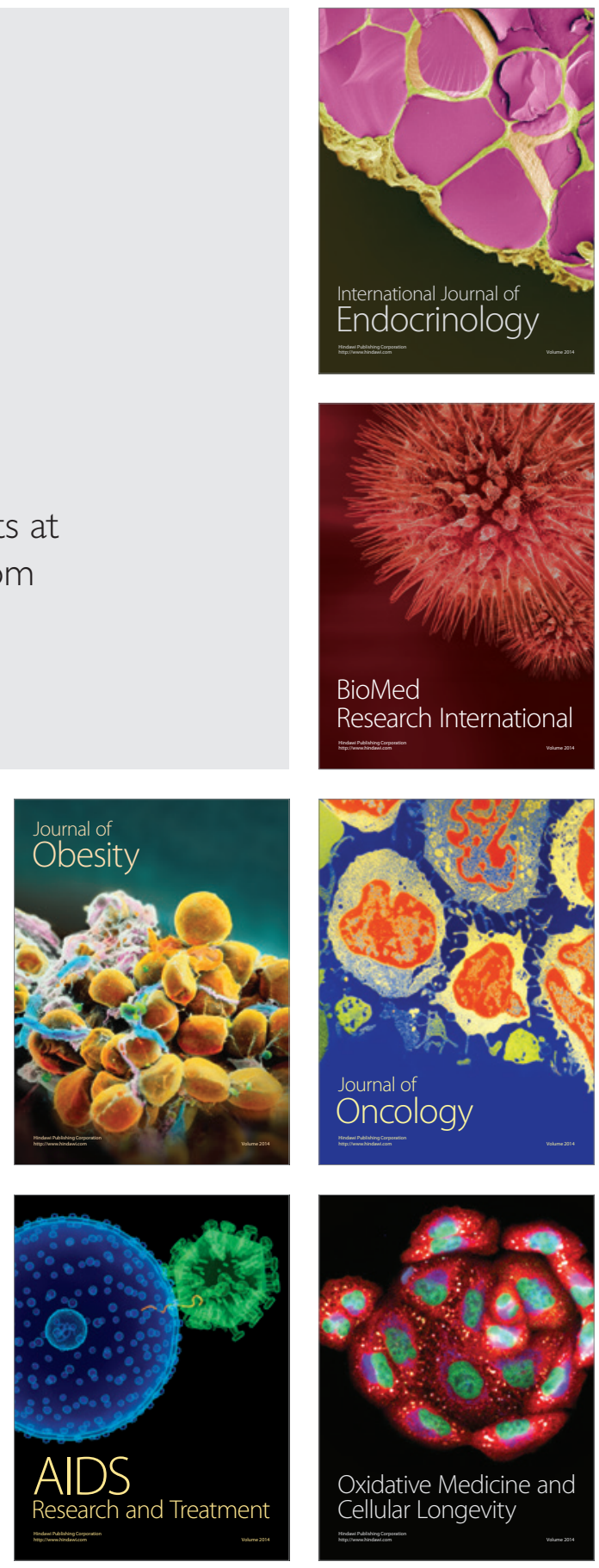